\title{
Design of AI-based gamification platform for effective educational service using child behavior prediction/change
}

\author{
HyeonWooNam ${ }^{1}$ \\ ${ }^{1}$ Computer Science, Dongduk Women’s Univ., SEOUL, Republic of Korea hwnam@dongduk.ac.kr ${ }^{1}$
}

Article History: Received: 11 January 2021; Accepted: 27 February 2021; Published online: 5 April 2021

\begin{abstract}
Due to the advancement of advanced technologies such as artificial intelligence, robots, autonomous vehicles, healthcare, virtual reality, augmented reality, etc. and the popularization of smartphones, it stimulates customer interest and leads voluntary participation in order to maximize interactive communication in all industries The gamification strategy incorporating games began to emerge. A representative field that generates results by easily introducing such a gamification strategy is the education industry that seeks to improve the educational effect by utilizing the elements of corporate marketing strategies and games such as challenge, competition, achievement, and reward. Recently, gamification research is being conducted to effectively apply $\mathrm{AI}$ and big data, the core technologies of the 4th industrial revolution in all industries. Gamification is actively forming markets in Europe and the US, and it can increase customer loyalty and productivity by applying various roles applied to games in other industries as well as serious games. The purpose of this study is to design and implement a gamification service platform based on artificial intelligence technology and operate the implemented system to expand the area where the gamification service applied to the existing marketing and consulting fields can be used. The designed gamification service platform can be applied to education services that increase learning efficiency by analyzing the predicted learning attitudes of trainees, and through successful research cases, it will be able to provide immersion effect to trainees and teaching method research to educators.
\end{abstract}

Keywords:Gamification, Gamification, CRM(Customer Relationship Management), SAP(Systems, Applications, and Products in data processing), ERP(Enterprise Resource Planning), DL(Deep Learning).

\section{Introduction}

With the rapid development of digital technologies such as 5G, artificial intelligence, blockchain, virtual reality, and augmented reality, and the spread of various smart devices that have become necessities for daily life, interactive communication between companies and consumers has been maximized.Gamification is a compound word of 'game' and ' fication', and it induces customer behavior by applying a game format to various industries [1].

The use of gamification is becoming more important for companies to study marketing strategies and effective teaching methods. The gamification marketing strategy is to apply gamification incorporating games to increase customer interest and active participation.

Bang. M. (2014) conducted a study on the principles of web site design and the concept, mechanism and components of gamification to establish basic design guidelines for gamification-oriented web site design. Through the research results, a design guideline was proposed that considers the color code, layout and effective strategy for applying the gamification methodology. The research results are expected to be used as basic resources when gamification-oriented web site design is needed [2].

Sungjin P. et al. (2020) conducts research to help understand work stress by analyzing the relationship between fun experiences, learning effects, delivery effects, and learning flows when teaching job stress using gamed board games in the work stress training course. For this study, a gamification board game was developed based on the gamification development methodology and the work transformation model of Karasek. Through the experimental results, it was found that game painters had a positive effect on the learning effect, delivery effect, and learning flow [3].

Dayeun C. et al. (2020) conducted a study to analyze how the visual design class using gamification affects the learning motivation and academic achievement of first-year high school learners. Teaching-learning programs and game tools were designed and developed based on theoretical considerations on this research topic. In the course of our research, we have developed tools to measure learning motivation and academic achievement to demonstrate the effectiveness of programs and game tools. Through the results of the study, students were interested in and actively participated in visual design classes and game tools using gamification, and found that they had a positive effect, such as increased understanding and interest in visual design[4].

Sungjin. P. et al. (2019) studied how to design gamification to improve gaming and digital addiction. For the study, we collected 782 gamification cases and analyzed the game mechanics and fun experiences through the 4F process to design effective gamification. In order to find a specific pattern, in the case of 782 cases, a preemptive algorithm to find related rules in transactions was applied. According to the results of the study, 63 rules related to game mechanisms and 37 related rules were found out of fun experiences, and were applied to suggest the direction of gamification design to improve games and digital addiction [5]. 
Kyungil. D. (2020) conducted a study to present the direction of gamification as an effective marketing strategy by identifying the implications of using gamification, which became a trend, and analyzing gamification techniques and factors that appeared in various cases. As a result of analyzing various types of marketing strategies used by companies, the important factors commonly recognized in gamification techniques used in marketing were'achievement' and'reward'. It turned out to be an effective strategy to induce consumer interest and participation by using various products and benefits obtained by solving a given mission or task as a game element, and to promote consumption by increasing consumer immersion [6].

In recent years, all industries are conducting gamification research that effectively applies AI and big data, which are the core technologies of the 4th industrial revolution that converges the boundaries of artificial intelligence, robot technology, life science, and physics.Gamification, which is actively forming markets around Europe and the United States, can improve customer loyalty and productivity by applying various dynamics applied in games to other industries, not just serious games. Gamification is a solution that improves customer loyalty and engagement by applying various dynamics (points, rankings, levels, badges, quests, etc.) applied ingame to other industries.

This study aims to expand the gamification service applied in the existing marketing and consulting fields to the field of teaching method research to enhance educational effectiveness by designing and implementing a gamification service platform based on artificial intelligence technology and operating the implemented system. First of all, after looking at the outline of gamification and describing the design method of the gamification service platform, the designed gamification service platform can be applied to educational services that improve learning efficiency by analyzing the predicted learning attitude of the trainee. Through this, we present the conclusion that it will be able to provide immersion effect to educators and pedagogy research to educators.

\section{Concept and characteristics of gamification}

\subsection{Definition and origin of gamification}

Gamification refers to the use of game design elements such as rules and objectives or game mechanics such as motivation and fun in areas other than games such as business, education, finance, and healthcare.The characteristics of Gamification can be broadly divided into gameplay, creativity, communication, rewards, and virality as follows [7]:

- Gameplay: Enjoy the game through competition based on rules

- Creativity: Efficient education and creation of UGC through self-directed execution

- Communication: Exchange through communication with other people and satisfaction through selfexpression

- $\quad$ Reward: Motivation through reward systems such as score, leaderboard, and prize money

- Virality: Rapidly spread and delivered through web and social media

Gabe Zichemann et al. (2011) defined Gamification asthe process of immersing users and solving problems using game-like thinking and techniques', and realizing the immersion, fun, and motivation that occur through game-like thinking and techniques. It suggested that the problem can be solved by applying it to various fields around the world. For example, change children's behavior to make broccoli fun and enjoyable by changing children's eating broccoli like a game, telling them to land a broccoli plane in their mouth, applying cheese sauce, and rewarding delicious desserts after eating broccoli $[8,12]$.

Huotari. K et al. (2011) defined Gamification as 'a form of a service package, including a rule-based service system and core services that provide interaction and feedback to users', and these are social media services, LinkedIn. ), and the stamp system of dry cleaning service as an example, explained that Gamification is used to increase the loyalty and convenience of customer service by using game elements [9, 13].

The term Gamification began to be widely used in the second half of 2010, and several terms similar to Productivity games,Funware and Behavioral games shown in the following Table (1) were used in parallel, but the term Gamification is the most widely accepted term in the industry. It has spread even more after the Gamification Summit \& Conference held in San Francisco, USA in January 2011.

Table 1. A term similar to gamification

\begin{tabular}{|c|c|}
\hline Term & \multicolumn{1}{c|}{ Meaning } \\
\hline $\begin{array}{c}\text { Producti } \\
\text { vity games }\end{array}$ & $\begin{array}{l}\text { The concept Microsoft used to define a } \\
\text { bug hunter, a kind of work productivity- } \\
\text { enhancing game in which testers pay each } \\
\text { time they find a bug to catch a software bug }\end{array}$ \\
\hline Funware & $\begin{array}{l}\text { A term used by journalist Dean } \\
\text { Takahashi to define trends in new concepts } \\
\text { such as alternative reality games that apply }\end{array}$ \\
\hline
\end{tabular}




\begin{tabular}{|c|l|}
\hline & $\begin{array}{l}\text { game mechanics and gaming behavior to } \\
\text { non-traditional video games }\end{array}$ \\
\hline $\begin{array}{c}\text { A term used by Aaron Dignan in his } \\
\text { Behavior } \\
\text { al games }\end{array}$ & $\begin{array}{l}\text { book, arguing that games are not a harmful } \\
\text { medium that causes addiction, but can be a } \\
\text { driving force behind a change in individual } \\
\text { behavior. }\end{array}$ \\
\hline
\end{tabular}

Source: Deterding, S.et al. (2011)

\subsection{Difference between serious game and gamification}

Gamification has similarities with serious game and playful design, but it shows distinctive features and can be seen as being located at different points as shown in Figure (1).",

Figure 1. Location of serious games and gamification

Source:Deterding, S. et al. (2011)

It can be said that both functional games and gamification are used in real life and real fields, not computer games for the purpose of only traditional entertainment (play). However, while a functional game has the whole form of the game, the biggest difference is that Gamification uses only the elements (elements, parts) of the game. In summary, functional games formally maintain the form of computer games, whereas Gamification can be implemented by applying game design elements to household chores such as web services, business work, laundry, and cleaning, not games [10].

\subsection{Case of gamification}

It is a solution that can be used in various fields from simple gamification such as Starbucks coupons to gamification interworking with CRM, ERP, and SAP. As shown in Figure (2), in 2012, Samsung Nation of Korea successfully applied a badgeville gamification to increase customer review registration by over $500 \%$ to obtain customer review data.

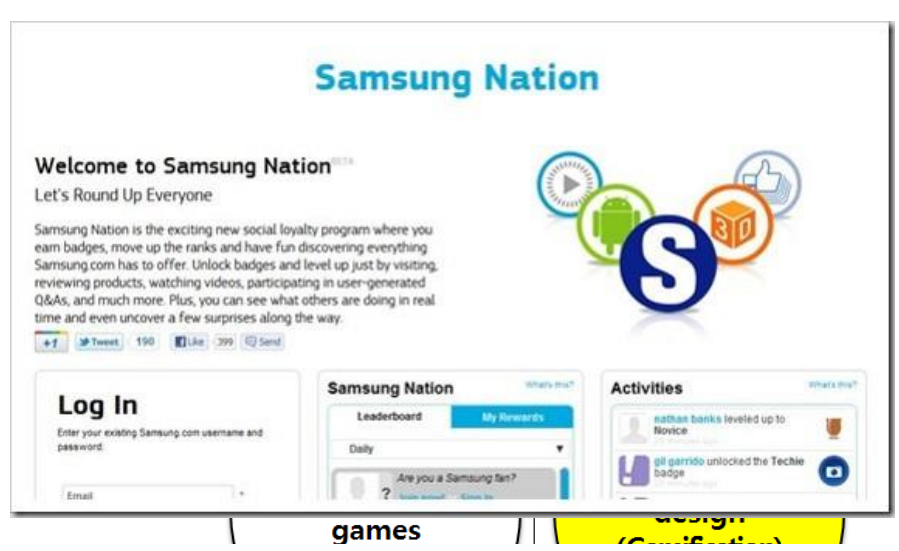

Figure 2. Case of Samsung NationSource: Samsung Nation Website (http://www.samsung.com/us/samsungnation)

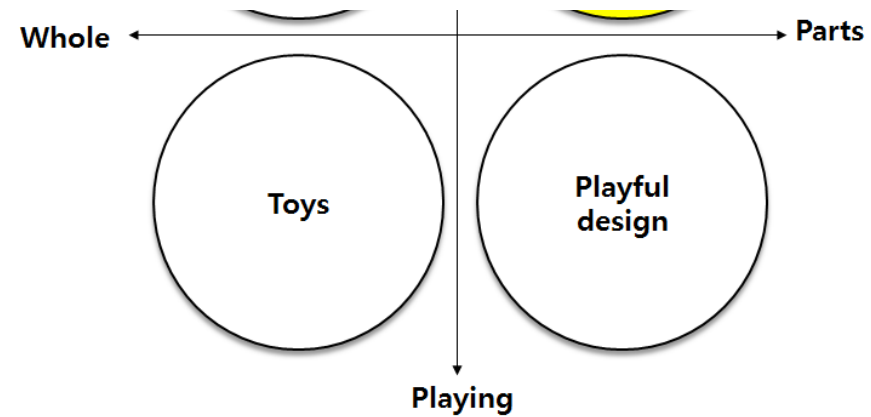

American gamification companies such as Badgeville, Bunchball, and Gigya provide game services that are variously linked to ERP and SAP, as shown in Figure (3).

In addition, Marriott, a hotel chain operator, introduced Gamification management techniques for public relations for hiring new employees and training internal employees. By providing "My Marriott Hotel," a game application based on hotel restaurant management through Facebook, it aims to spread the interest of young users in the hotel industry and expand the number of recruitment targets [11]. 
Through various domestic and overseas cases, it was analyzed that Gamification is being used in various fields such as healthcare, customer loyalty enhancement, corporate work, various consumption, pursuit of behavioral changes such as saving, politics, and learning.

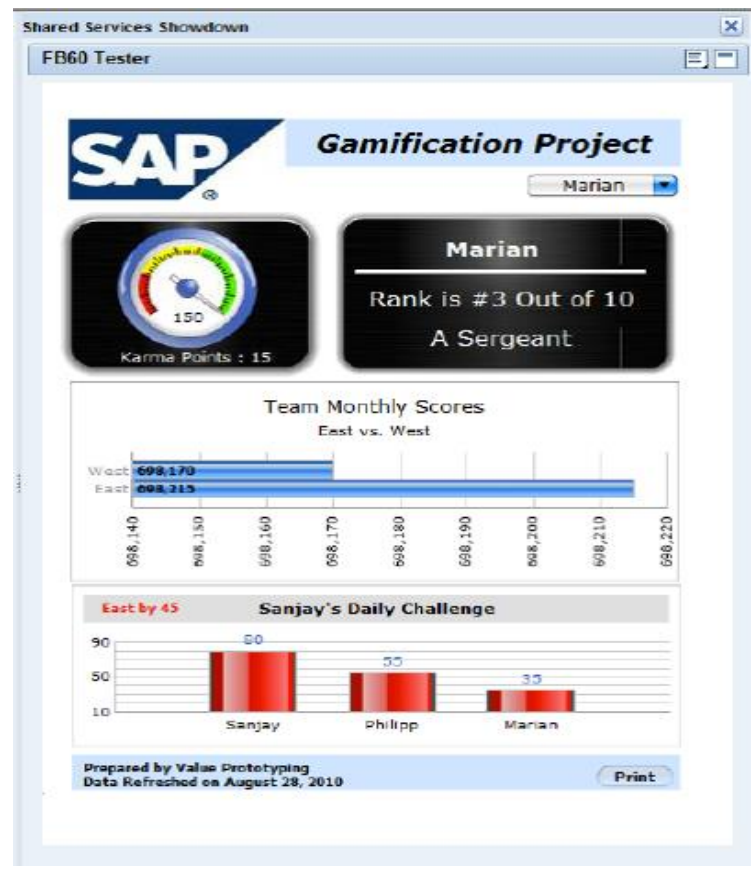

Figure 3. Case of SAP

Source:SAP Website (https://experience.sap.com/)

\subsection{Game elements used in gamification}

Game elements used for gamification are largely fun elements, scores, levels, ranking, badges, and quests, and the key features are as follows [7];

- Fun Elements: Various game techniques and systems can be devised by using fun factors such as pattern recognition, collection, treasure hunt, gift exchange, and achievement recognition.

- Scores: There are 'experience points' that accumulate points for all actions performed within the Gamification system, 'liquidity points' that can be used to change or purchase something after accumulating, and 'skill points' that are given for acquiring various skills. . Track and value every player's actions, and score how players perform within the system.

- Level: Used as a sign indicating how far the player has advanced in the game, and indicates how far the individual has completed the mission.

- $\quad$ Ranking: This is a table showing the ranking of the players, and it plays a role in determining one's position and stimulating the willingness to challenge.

- $\quad$ Badge: serves as a reminder of people's status and status, and acts as a powerful motivator for obtaining a better badge.

- Quest: refers to a challenge, arouses a sense of challenge and curiosity in the game, induces interest in the process of solving a challenge individually or through cooperation, and generates a positive response through a reward system given after completion.

\section{Proposed gamification service platform}

The contents of this study can be largely divided into the design of educational services to improve learning efficiency by analyzing the predictions of trainees' learning attitudes by operating and implementing a system that implements and implements a gamification service platform based on artificial intelligence technology. First, in order to build a gamification service platform based on artificial intelligence technology, designed and implemented a service platform applies deep learning technologies such as rule engines and recommended AI to applicable open source based gamification service APIs.Next, designed and developed a gamification app is to provide learning attitude prediction and learning guidance quests. It can be linked with the implemented service platform. Finally, after running the service by linking the implemented service platform with the gamification app, the data collected through the result analysis is conducted through deep learning to provide effective 
learning information recommendations or data to improve teaching methods. The availability of the system was evaluated.

\subsection{Designed System}

Figure (4) shows the overall structure of the proposed AI-based gamification platform.

Figure 4. Overview of designed System

The items and core functions to be developed to satisfy the proposed system in Figure (4) are as follows;

- Interactive quest system core: Development of a one-way activity-oriented quest system as a two-way (according to user feedback) quest system

- Quest Recommendation AI: Artificial intelligence that analyzes user big data and recommends appropriate quests

- Quest management dashboard: Dashboard including statistics for interactive quest management

- $\quad$ Quest Front UI: Frontend UI to expose quests to users

- Chance Game Quest Content: Additional development of chance games for various types of fun quests other than roulette

- $\quad$ Interactive Quest API: Open API for 3rd party to use game key service

- $\quad$ Pattern analysis AI: Behavior prediction AI through pattern analysis to determine if there are any risk factors based on big data such as user's location, moving line, progress quest, check-in, etc.

- Game graphics resources: Characters and worlds that can stimulate users' curiosity

- $\quad$ Behavior pattern API: OpenAPI to allow 3rd party to access user information

- $\quad$ Service application: Hybrid app type application

- Behavior Pattern Information Dashboard: CMS that can check the status of user monitoring and management

- $\quad$ AI \& Gamification Integration: Integrated interlock

3.2 Implementation result

Figure (5) shows before and after custom quest progress.

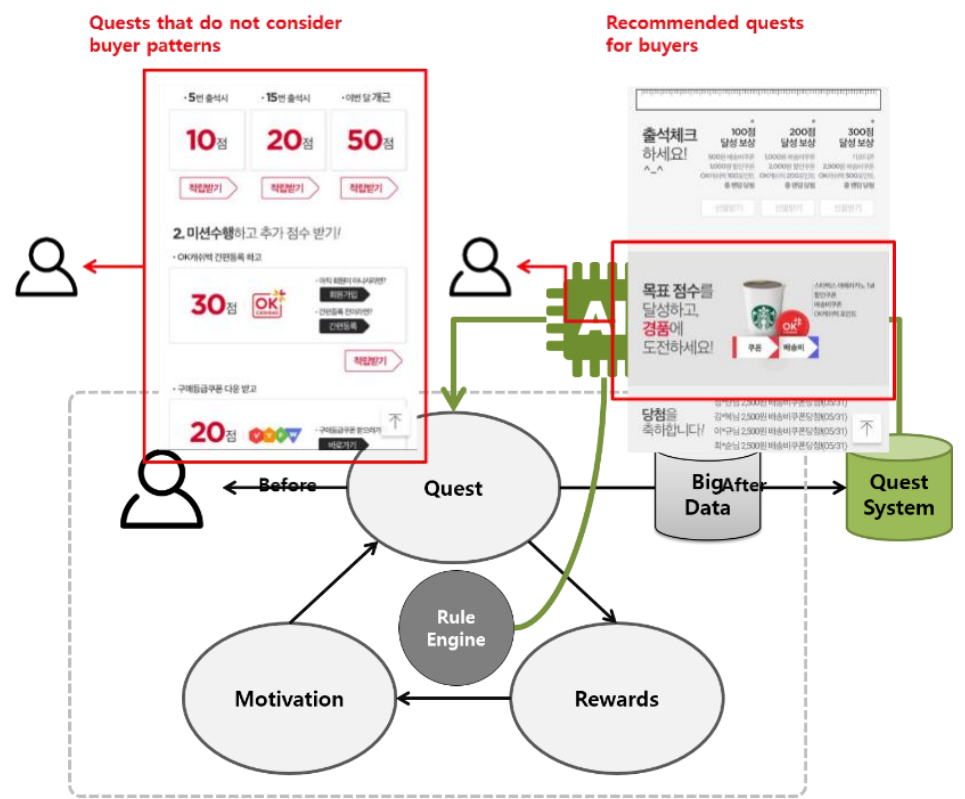

Figure 5. Before and after custom quest progress

As shown in Figure (5), the results of this study can help companies conduct online marketing more effectively through sophisticated gamification

If the proposed system is applied to a web service that induces customers to purchase and revisit products based on gamification techniques, it will solve the vulnerability of the existing recommendation system. 


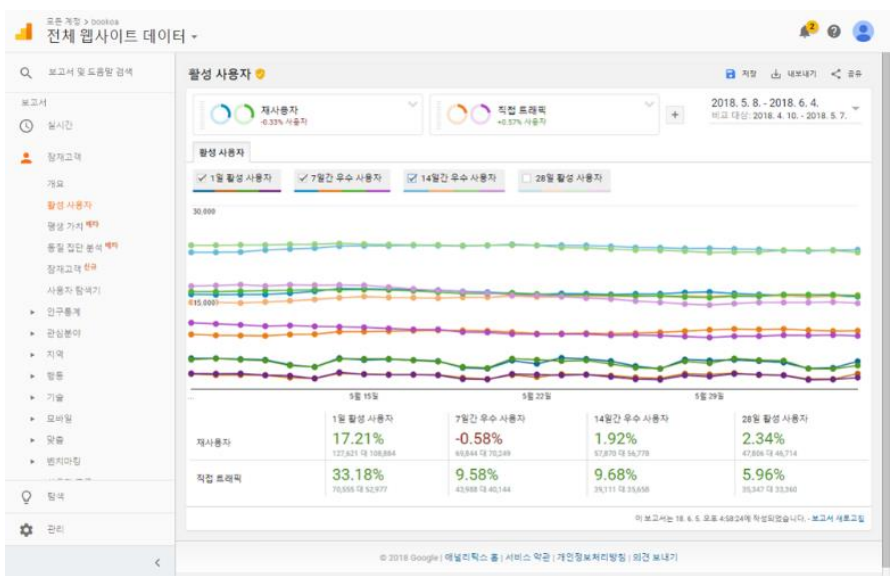

Figure 6. Effects of the gamification service

Figure(6) is a graphical representation of the existing effects of the gamification service to which the proposed system will be applied.The gamification used in the proposed system can make the children's hearts express the most honest and active. Through this, it is determined that AI can provide behavior correction quests through children's quest data and be used for public service such as child care services to determine emergency situations.

The implemented gamification service platform applied the gamification technique to shopping malls or community sites to actively expand customer loyalty and user activities. Web services based on the gamification technique do not simply accumulate when customers who enter the website using the service purchase products, but allow users to play basic chance games and play the corresponding game. Through the application of the logic to pay mileage, etc., it was induced to revisit.

Users can use the winning mileage when purchasing products on the website, and separate activities are given as points so that they can raise their level. The gamification service applied in this way induces increased loyalty and user behavior as shown in Table (2).

Table 2. Effects of gamification service

\begin{tabular}{|c|c|c|}
\hline Item & Effect & Remark \\
\hline $\begin{array}{c}\text { User } \\
\text { participation rate }\end{array}$ & $\begin{array}{r}30 \% \\
\text { increase }\end{array}$ & $\begin{array}{c}\text { Google } \\
\text { Analytics analysis } \\
\text { results }\end{array}$ \\
\hline User stay rate & $\begin{array}{l}\quad 6.75 \% \\
\text { increase }\end{array}$ & $\begin{array}{c}\text { Google } \\
\text { Analytics analysis } \\
\text { results }\end{array}$ \\
\hline $\begin{array}{l}\text { User revisit } \\
\text { rate }\end{array}$ & $\begin{array}{r}12 \% \\
\text { increase }\end{array}$ & $\begin{array}{c}\text { Google } \\
\text { Analytics analysis } \\
\text { results }\end{array}$ \\
\hline
\end{tabular}

In addition, if users are guided to other pages through roulette rather than staying on the roulette page, and add roulette to the induced page, it is determined that more active customer activity induction will be possible.

The gamification used in the proposed system can make the children's hearts express the most honest and active. Through this, it is determined that AI can provide behavior correction quests through children's quest data and be used for public service such as child care services to determine emergency situations.

\section{Conclusions}

In this paper, a gamification service platform based on artificial intelligence technology was designed and implemented to expand the available range of gamification services applied to the existing marketing and consulting fields, and the implemented platform was applied as a marketing tool for the website. The research was conducted.

The effect of gamification was proven by first applying the implemented gamification service platform for web service marketing to derive meaningful results.

Recently, it is reported that the number of teenagers who feel suicidal or try to commit suicide directly due to school violence, bullying, depression, and health concerns is increasing. In particular, in dual-income families or 
caring families, children never talk about their worries, and it is judged that a way to know the hearts of children and to prevent emergency situations in advance is necessary.

Since there are many attempts to directly apply gamification techniques to general education methods, the follow-up study of this study aims to develop a service that can judge and cope with such adolescents' emergency situations.

Research to prevent emergency situations through prediction of adolescents' behavioral reading can be used as an educational service to increase learning efficiency by analyzing learning attitude prediction. It is believed that the successful application of the research results will be effective in inducing and motivating trainees to learn, and will be of great help to teaching method educators.

\section{Acknowledgment}

This research was supported by the Dongduk Women's University grant.

\section{References}

1. NAVERCAST.

(2015).

NAVERCAST.

Gamification. https:///terms.naver.com/entry.nhn?docId=3579504\&cid=59088\&categoryId=59096.

2. Junsik. M. (2014). A Study on the Design Guidelines for the Gamification oriented Web-Sites. Journal of Basic Design \& Art, 15(2), 141-151.

3. Sungjin. P., Jintae J., Eunhye. H., Jaehyen. I., and Sangkyun. K. (2020). The Effect of Gamified Board Game on Job Stress Education. Journal of Digital Contents Society, 21(6), 1069-1078.

4. Dayeun. C., and Hyojung K. (2020). The Influence of Visual Design Class using Gamification on the Learning Motivation and Academic Achievement of Firstyear High School Learners. Archives of Design Research, 33(2), , 215-228.

5. Sungjin. P., and Sangkyun. K. (2019). A Proposal of Gamification Design Elements to prevent Game and Digital Addiction. Journal of Korea Game Society. 19(1), 95-107.

6. Kyungil. D. (2020) Case Study on Using Gamification as an Effective Marketing Strategy. Journal of Digital Convergence, 18(2), 395-401.

7. KOCCA CT INSIGHT. (2013). Gamification Trends and Cases. KOCCA CT INSIGHT, 30(6), 541.

8. Zichemann, G., \& Cunningham, C.(2011). Gamification: Gamification by Design: Implementing Game Mechanics in Web and Mobile Apps. O'REILLY. Available at http://shop.oreilly.com/product/0636920014614.do

9. Huotari, K., \&Hamari, J.(2011). Gamification from the perspective of service marketing. In Proc. CHI 2011 Workshop Gamification.

10. Deterding, S., Dixon, D., Khaled, R., \&Nacke, L.(2011). From game design elements to gamefulness: defining gamification. In Proceedings of the 15th International Academic MindTrek Conference:Envisioning Future Media Environments, 9-15.

11. Marriott. (2013). http://www.blogs.marriott.com/marriott-on-the-move/2011/06/get-a-tastefor-whatit-takes-at-my-marriott-hotel.html)

12. Aksu, G., \&ReyhanliogluKeceoglu, C. (2019). Comparison of Results Obtained from Logistic Regression, CHAID Analysis and Decision Tree Methods. Eurasian Journal of Educational Research, 84, 115-134.

13. Aras, A. (2019). The Effect of Mobbing Levels Experienced by Music Teachers on Organizational Commitment and Job Satisfaction. Eurasian Journal of Educational Research, 84, 29-56. 